University of South Carolina

Scholar Commons

$2-2002$

\title{
Correlates of Vigorous Physical Activity for Children in Grades 1 Through 12: Comparing Parent-Reported and Objectively Measured Physical Activity
}

\author{
James F. Sallis \\ Wendell C. Taylor \\ Marsha Dowda \\ University of South Carolina - Columbia, mdowda@mailbox.sc.edu \\ Patty S. Freedson \\ Russell R. Pate \\ University of South Carolina - Columbia, rpate@mailbox.sc.edu
}

Follow this and additional works at: https://scholarcommons.sc.edu/

sph_physical_activity_public_health_facpub

Part of the Public Health Commons

Publication Info

Published in Pediatric Exercise Science, Volume 14, Issue 1, 2002, pages 30-44.

Sallis, J. F., Taylor, W. C., Dowda, M., Freeson, P. S., \& Pate, R. R. (2002). Correlates of vigorous physical activity for children in grades 1 through 12: Comparing parent-reported and objectively measured physical activity. Pediatric Exercise Science, 14(1), 30-44.

(C) Pediatric Exercise Science, 2002, Human Kinetics

This Article is brought to you by the Physical Activity and Public Health at Scholar Commons. It has been accepted for inclusion in Faculty Publications by an authorized administrator of Scholar Commons. For more information, please contact digres@mailbox.sc.edu. 


\title{
Original Research
}

Pediatric Exercise Science, 2002, 14, 30-44

(C) 2002 Human Kinetics Publishers, Inc.

\section{Correlates of Vigorous Physical Activity for Children in Grades 1 Through 12: Comparing Parent-Reported and Objectively Measured Physical Activity}

\author{
James F. Sallis, Wendell C. Taylor, Marsha Dowda, \\ Patty S. Freedson, and Russell R. Pate
}

Correlates of physical activity were examined in young people in grades 1 through 12 , and analyses were conducted separately for eight age/grade and sex subgroups. Twenty-one explanatory variables were assessed by parental report. Physical activity was assessed in 781 young people via parent report, and 200 wore an accelerometer for seven days. Between $11 \%$ and $36 \%$ of parent-reported child vigorous physical activity was explained. The most consistent correlates were peer support and use of afternoon time for active rather than sedentary recreation. Peer support was the only significant correlate of objectively monitored activity in multiple subgroups.

Studies of correlates of youth physical activity are important because they can answer basic questions about likely influences on the behavior and can inform the design of intervention studies. Reviews of these studies have identified significant correlates in all domains examined, including demographic, psychological, biological, social, and physical environmental $(3,13,14,16,17,18,19)$. The wide range of correlates supports the application of ecological models of behavior to improve understanding of the influences on youth physical activity. Ecological models posit multiple domains of variables influence behavior, and other more specific theories can be incorporated into broad ecological frameworks (10). The present study was based on an ecological model of physical activity and investigated demographic, psychological, social, and environmental variables as potential correlates of youth physical activity.

Despite over 100 published studies of youth physical activity correlates (13), there are many gaps in the literature. Developmental changes during youth include substantial declines in physical activity with age $(7,9,18)$. However, few studies of physical activity correlates have reported associations for children of various ages so developmental differences in correlates can be examined (14). The present

J.F. Sallis is with the Department of Psychology at San Diego State University. W.C. Taylor is with the School of Public Health at University of Texas-Houston Health Science Center. M. Dowda and R.R. Pate are with the Department of Exercise Science, University of South Carolina. P.S. Freedson is with the Department of Exercise Science, University of Massachusetts at Amherst. 
study is the first to report on a sample of young people from all school grades, with separate analyses for four grade-based subgroups. Similarly, there are consistently documented sex differences in activity levels, indicating males are more active than females at all ages $(7,9,13,18)$. The present study reports associations separately for males and females.

The least studied domains of correlates of youth physical activity are social factors (other than parental modeling) and physical environment factors $(13,17)$. Therefore, one purpose of the present study was to expand the assessment of these domains. For example, in the social domain, the present study included assessments of modeling, verbal encouragement, and participation with the child from family members and peers. This is a more complete examination of potential social influences than has been reported previously. The small list of previously studied physical environmental variables was expanded substantially. Parents reported on the presence of neighborhood characteristics that could positively or negatively influence physical activity (12). Other new items assessed perceived safety of the neighborhood for young people to play outdoors without supervision and access to activity facilities. Three items assessed distance to the nearest park, safety of that park, and frequency of using the park.

A major limitation of the vast majority of studies of correlates of youth physical activity is they rely solely on self-reported measures of physical activity. Studies of adults suggest different patterns of associations are found when results with self-reported and objectively measured physical activity are compared (4). These findings call into question the validity of studies with self-reported measures.

The purpose of the present study was to assess correlates of physical activity in subgroups of young people that differ in age and sex. This study fills gaps in the literature by recruiting young people from grades 1 through 12, expanding assessments of social and physical environmental variables, and assessing physical activity with both parent-report and objective measures. Only vigorous activities were examined in the present study, because these salient activities appear to be most reliably reported, and it is expected that participants refer mainly to vigorous activities when reporting variables used as correlates.

\section{Method}

\section{Subjects}

Participants were recruited from children in grades 1 through 12 enrolled in physical education in the public school system in Amherst, MA and surrounding towns. There was one junior high and one senior high in Amherst, and both participated. Four of the seven elementary schools in this study were in Amherst, and the other three were in Leverett, Shutesbury, and Pelham.

\section{Procedure}

Prior to in-school visits by the research team, permission was obtained from the superintendent of schools and officials at each school. The study was approved by appropriate Institutional Review Boards. During initial visits, the objectives of the study were explained to children during physical education classes. Children were given a packet of materials that included letters of support, an incentive worth $\$ 1.00$, an informed consent, and a parent survey. Children who returned the parent 
questionnaire and informed consent received another incentive worth $\$ 1.00$. Students in grades 7 through 12 who returned completed parent surveys were administered a student-report survey during physical education class. The student survey was not used in the present analyses.

About 3,648 surveys were distributed during November and December 1996, and the number of usable parent surveys was 1164 (32\%). If more than one child from a family returned a parent survey, one child's survey was randomly selected for inclusion in the data base, which reduced the sample to 1091. Surveys with incomplete data were deleted, leaving 781 participants for the survey analyses. The sample was $48.1 \%$ male, was $76.9 \%$ non-Hispanic white, and participated in $3.1(S D=2.8)$ activity teams and classes.

The goal for the monitoring portion of the study was to obtain 100 (50 of each sex) subjects per age group. Age groups were defined as: grades 1-3, grades 4-6, grades 7-9, and grades 10-12. Participants invited to be in the monitoring study were randomly selected from each age group.

Children chosen for the CSA monitoring were contacted by phone to verify that consent had been obtained from both the parent and the child. Elementary school children (grades 1 through 6) received monitors either at the beginning of the day or during lunch. Secondary school students (grades 7 through 12) received their monitors at the beginning of their physical education class. Monitors were distributed equally across age groups during any given week to control any confounding effects of weather.

Each child received one CSA model 7164 monitor. Students were instructed to wear the monitor on the right hip at all times for seven days, except when swimming, showering, or sleeping. A log sheet was provided to record the times when the monitor was not worn and to provide information on activities done while the monitor was off.

The child or parent was contacted via phone 1-2 days prior to monitor collection. Monitors were typically collected at a slightly later time of day than the attachment time to ensure seven complete days of data. The children who completed this portion of the study received monetary compensation $(\$ 20.00)$ and an entry in a raffle for sporting event tickets. After collection, monitors were downloaded to an IBM compatible computer, and the data were reviewed for negative count values (indicative of monitor failure) and long periods with zero values (indicative of taking the monitor off).

CSA monitor data collection was conducted in two waves. The first wave was in November 1996, and 200 students completed the seven days of data collection and had complete questionnaires. The second wave was in March 1997, and 65 students wore the CSA and had complete questionnaires. Data collection was avoided in the Winter because the cold weather was expected to reduce children's opportunities to be active (18). For present analyses only the 200 subjects monitored in the Fall were included in the analyses, so the questionnaire and monitor data were collected around the same time. The monitor subsample was very similar in demographic characteristics when compared to the survey sample.

\section{Measures}

Questionnaires. Two questionnaires were used; a parent-report survey for all grades and a self-report survey for students in grade seven and above. The 
parent survey was 10 pages and assessed the child's physical activity and potential correlates of youth activity in demographic, psychological, social, and physical environmental domains. The survey was designed to be relevant to all children in grades 1 through 12. In developing the survey, an emphasis was placed on creating more detailed assessments of social and physical environmental variables than had been included in previous studies. The 21 variables that were derived from this survey are described in Table 1, along with reliability data. Some items were drawn from other surveys, but most were written for the present study. All items were pilot tested in four regions of the U.S. for comprehension, and revisions were made. A reliability study of this questionnaire was conducted and is described below. The survey required approximately $45 \mathrm{~min}$ to complete. (A table reporting percents or means for each study variable from the survey by sex and grade-group is available upon request from the first author.)

To estimate the child's activity during the previous seven days, 46 physical activities and sedentary behaviors were listed, with three spaces for "other" activities. Respondents indicated whether the activity was done and if so, on how many days and how many min per day the activity was performed. Each activity was assigned an intensity value, based on the Compendium of Physical Activities (1), and total time was multiplied by intensity to compute a total caloric expenditure per kilogram of body weight. Additional questions were asked about sports team participation and activity classes.

Activity Monitor. The activity monitor used in this project was the CSA, model 7164 (Computer Science and Applications, Shalimar, FL) which measured integrated accelerations in the vertical plane. Each CSA weighs 56.7 grams and is $5 \times 5 \times 1.5 \mathrm{~cm}$ which makes it similar in size to a wristwatch. This monitor has been validated against oxygen consumption during treadmill locomotion with Pearson and Intraclass $r \neq 0.84$ (6). The CSA 7164 had moderate correlations with a 3-day activity diary $(r=0.51)$ and seven day recall $(r=0.52)(15)$ which were similar to values obtained when comparing these instruments with a Caltrac monitor.

The CSA monitors were attached to the subjects' right hips using an elastic strap that reduced extraneous movements. Each data point represented one sample of activity data (i.e., the quantity of the vertical accelerations during the specified sampling interval). For this study, a one-min sampling interval was used to allow detailed movement patterns to be analyzed. When the unit was initialized data collection began, and activity counts were stored in the internal memory. At the end of data collection, min-by-min results were downloaded to a personal computer using a special interface.

\section{Scoring and Data Analysis}

CSA Data Reduction. Minute-by-minute activity counts were transferred to a QBASIC data reduction program that calculated total counts and min of moderate (3-5.9 METs), vigorous (6-8.9 METs), and very vigorous physical activity ( $\neq 9$ METs) for each 60-min segment of the 7-day monitoring period, using the age-specific count cutoffs established by Freedson and co-workers (5). Activity totals for each day and week were calculated.

Computing correlates of physical activity. For scales, confirmatory principal components analysis with varimax rotation was used to check for unidimensionality, which was confirmed for all scales. Scale scores were created by sum- 
Table 1 Description of Parent-Reported Potential Correlates of Youth Physical Activity

\begin{tabular}{|c|c|c|c|c|}
\hline Variable name & $\begin{array}{l}\text { \# Items } \\
\text { [range] }\end{array}$ & $\begin{array}{l}\text { Description, } \\
\text { sample items }\end{array}$ & $\begin{array}{l}\text { Cronbach } \\
\text { alpha }\end{array}$ & $\begin{array}{l}\text { reliab } \\
(\mathrm{ICC})\end{array}$ \\
\hline \multicolumn{5}{|c|}{ Demographic variables } \\
\hline Parent education & $\begin{array}{l}1 \\
{[1,8]}\end{array}$ & $\begin{array}{l}\text { Parent education; } \\
\text { 1= High school or less, } \\
\text { 8=Doctorate degree }\end{array}$ & N/A & .77 \\
\hline Dual parent status & $\begin{array}{l}1 \\
{[0,1]}\end{array}$ & $\begin{array}{l}\text { Both parents in the home; } \\
\text { No, Yes }\end{array}$ & N/A & .85 \\
\hline Child's race/ethnicit & $\begin{array}{l}y 1 \\
{[0,1]}\end{array}$ & $\begin{array}{l}\text { Child's racial/ethnic group; } \\
\text { White, Other }\end{array}$ & N/A & 1.00 \\
\hline No. children in hom & 1 & Number of children $<18$ & N/A & .93 \\
\hline \multicolumn{5}{|c|}{ Child psychological \& biological variables } \\
\hline $\begin{array}{l}\text { Body mass index } \\
(\mathrm{BMI})\end{array}$ & $\begin{array}{l}2 \\
{[10,45]}\end{array}$ & $\begin{array}{l}\text { weight in } \mathrm{kg} / \text { (height }^{2} \\
\text { in meters) }\end{array}$ & N/A & .93 \\
\hline School grades & $\begin{array}{l}1 \\
{[1,3]}\end{array}$ & $\begin{array}{l}\text { Child's most common } \\
\text { grades in school; 1=A's } \\
\& \text { B's, 2=C's, 3=D's \& F's }\end{array}$ & N/A & .73 \\
\hline Enjoyment of PE & $\begin{array}{l}1 \\
{[0,5]}\end{array}$ & $\begin{array}{l}\text { Does child enjoy PE class; } \\
0=\text { not enrolled, } 1=\text { un-enjoyable, } \\
5=\text { very enjoyable }\end{array}$ & N/A & .81 \\
\hline $\begin{array}{l}\text { Enjoyment of } \\
\text { physical activity } \\
\text { (PA) }\end{array}$ & $\begin{array}{l}1 \\
{[1,5]}\end{array}$ & $\begin{array}{l}\text { Does child enjoy physical } \\
\text { activity; } 1=\text { unenjoyable, } \\
\text { 5=very enjoyable }\end{array}$ & N/A & .87 \\
\hline Coordination & $\begin{array}{l}1 \\
{[1,5]}\end{array}$ & $\begin{array}{l}\text { Comparison of child's athletic } \\
\text { coordination; } 1=\text { much less, } \\
5=\text { much more than peers }\end{array}$ & N/A & .81 \\
\hline $\begin{array}{l}\text { Use of recreational } \\
\text { time }\end{array}$ & {$[1,5]$} & $\begin{array}{l}\text { What does the child usually do; } \\
\text { 1=Almost always watch TV, } \\
\text { read, music, computers, } \\
\text { 2=Usually watches TV, read, } \\
\text { music, computers, } 3=\text { Just as } \\
\text { likely to choose active as } \\
\text { inactive recreation, } 4=\text { Usually } \\
\text { biking, dancing outdoor games, } \\
\text { active sport, 5=Almost always } \\
\text { bike, dance, outdoor games, } \\
\text { active sports }\end{array}$ & N/A & .88 \\
\hline
\end{tabular}




$\begin{array}{lll}\text { Diet quality } & 7 & \begin{array}{l}\text { Frequency of healthy or } \\ \text { unhealthy food; Healthy: fresh } \\ \text { fruit, fruit juice, salad, cooked } \\ \text { vegetables. Unhealthy: ham- } \\ \text { burger/hot dog/sausage, french } \\ \text { fries/potato chips, cookies/ } \\ \text { doughnuts/pie/cake }\end{array}\end{array}$

\section{Social variables \\ Family influences}

Adult physical activity

Environmental variables

Neighborhood 8
characteristics

Neighborhood safety

Access to facilities 1

Park distance

1

Park safety

1

Park frequency

$$
\text { Frequency with which family; }
$$
provided transportation, watched child play sports, told child that physical activity was good for health
Highest adult physical activity N/A score created from reported minutes walking, house chores, gardening, and sport participa- tion.Minutes $\mathrm{x}$ METs=MET minutes.

Frequency that child's five active, friends encourage to be active, friends are active with subject

Presence of sidewalks, heavy N/A .78 traffic, hills, street lights, unattended dogs, enjoyable scenery, see people walking for exercise, high crime

Safe to play outdoors without

N/A adult supervision; $1=$ strongly disagree, 5=strongly agree Access to playgrounds, parks or gyms; $1=$ strongly disagree, $5=$ strongly agree 
ming the scores of items. Cronbach's alpha was employed to assess internal consistency of each scale, and these are reported in Table 2.

Computing reported physical activity. Physical activity min as reported by parents were corrected for gross errors by Windsorizing. This process corrects errors and large aberrations in distributions by eliminating the highest or lowest values and replacing them with the next highest or lowest values. In this sample several responses were extremely high, and they were replaced with values based on the 90 th or 99 th percentile values.

The outcome variable was $\mathrm{kcal} / \mathrm{kg} / \mathrm{day}$ of vigorous physical activity. This variable was computed by summing daily min in reported vigorous physical activity, based on activities with a MET intensity of 6 or greater according to the Compendium of Physical Activities (1). The days per week and min per day reported for

Table 2 Spearman Correlations Between 21 Potential Determinants and Parent-Reported Vigorous Physical Activity in Eight Subgroups of Students Defined by Age and Grade Group

\begin{tabular}{|c|c|c|c|c|c|c|c|c|c|}
\hline \multirow[b]{3}{*}{ Variable } & \multirow[b]{2}{*}{ Grade } & \multicolumn{4}{|c|}{ Males } & \multicolumn{4}{|c|}{ Females } \\
\hline & & $1-3$ & $4-6$ & $7-9$ & $10-12$ & $1-3$ & $4-6$ & $7-9$ & $10-12$ \\
\hline & $\mathrm{N}$ & 71 & 100 & 128 & 76 & 74 & 99 & 126 & 105 \\
\hline \multicolumn{2}{|l|}{ Age } & .20 & .16 & -.02 & $-.41 * * *$ & .16 & .16 & .03 & -.05 \\
\hline \multicolumn{2}{|c|}{ Child race/ethnicity } & .05 & .11 & .11 & $.29 *$ & -.09 & .06 & .10 & .11 \\
\hline \multicolumn{2}{|c|}{ Parent education } & -.17 & -.13 & .03 & -.10 & -.13 & .01 & -.04 & -.07 \\
\hline \multicolumn{2}{|c|}{ Dual parent status } & $-.28^{*}$ & .05 & .04 & -.07 & -.11 & -.11 & -.16 & .01 \\
\hline \multicolumn{2}{|c|}{ No. children } & .11 & -.03 & $.20 *$ & .08 & -.06 & -.02 & .16 & .08 \\
\hline \multicolumn{2}{|l|}{ BMI } & -.07 & .17 & -.08 & -.09 & .21 & -.02 & -.07 & -.01 \\
\hline \multicolumn{2}{|c|}{ School grades } & .16 & .07 & .01 & -.12 & -1 & .04 & .08 & -.05 \\
\hline \multicolumn{2}{|c|}{ Enjoyment of PE } & .13 & .18 & -.01 & .13 & $.31 *$ & $.40 * * *$ & $.23 *$ & .17 \\
\hline \multicolumn{2}{|c|}{ Enjoyment of PA } & .09 & $.51 * * *$ & $.39 * * *$ & $.32 * *$ & .21 & $.42 * * *$ & $.33 * * *$ & $.28 * *$ \\
\hline \multicolumn{2}{|c|}{ Coordination } & .15 & $.35^{* * *}$ & $.39 * * *$ & .20 & .05 & $.38 * * *$ & $.22 *$ & $.39 * * *$ \\
\hline \multicolumn{2}{|c|}{$\begin{array}{l}\text { Use of recreational } \\
\text { time }\end{array}$} & .09 & $.41 * * *$ & $.49 * * *$ & $.24 *$ & .03 & $.28^{*}$ & $.46^{* * *}$ & $.45^{* * *}$ \\
\hline \multicolumn{2}{|c|}{ Diet quality } & .20 & .06 & $.26 * *$ & .09 & -.10 & .10 & .09 & .09 \\
\hline \multicolumn{2}{|c|}{$\begin{array}{l}\text { Adult physical } \\
\text { activity }\end{array}$} & -.02 & $.23 *$ & .13 & .22 & -.06 & .09 & -.10 & .004 \\
\hline \multicolumn{2}{|c|}{ Family influences } & .08 & $.41 * * *$ & $.22 *$ & $.25^{*}$ & .02 & $.22 *$ & $.20^{*}$ & $.38 * * *$ \\
\hline \multicolumn{2}{|c|}{ Peer influences } & $.30 *$ & $.35^{* * *}$ & $.52 * * *$ & $.37 * * *$ & $.26^{*}$ & $.30 * *$ & $.41 * * *$ & $.35 * * *$ \\
\hline \multicolumn{2}{|c|}{ Neighborhood chars. } & -.05 & -.04 & .003 & -.03 & -.01 & .08 & .13 & .07 \\
\hline \multicolumn{2}{|c|}{ Neighborhood safety } & .07 & .19 & .17 & .17 & .11 & -.03 & .10 & $.24 *$ \\
\hline \multicolumn{2}{|c|}{ Access to facilities } & .07 & .13 & .14 & .05 & -.01 & .11 & -.03 & .21 \\
\hline \multicolumn{2}{|c|}{ Park distance } & -.07 & -.07 & .02 & -.14 & .11 & .03 & -.05 & -.03 \\
\hline \multicolumn{2}{|c|}{ Park safety } & .09 & .08 & .07 & .001 & -.15 & -.11 & $-.18^{*}$ & .17 \\
\hline \multicolumn{2}{|c|}{ Park frequency } & -.06 & $.24 *$ & .11 & .10 & .08 & .05 & .08 & .14 \\
\hline
\end{tabular}

${ }^{1}$ Correlation could not be computed because all participants gave same response (all A's and B's) 
these activities was multiplied by the MET value, then the product was divided by 7 to yield $\mathrm{kcal} / \mathrm{kg} / \mathrm{day}$ of reported vigorous activity. The outcome was limited to vigorous intensity activities, because it was expected that participants used vigorous activities as referents when answering items related to many of the potential correlates. That is, respondents are likely to be thinking about vigorous activities when completing survey items on self-efficacy, social support, use of recreational time, etc. In addition, adult studies show psychosocial variables explain more variance in vigorous than moderate intensity activities (11).

CSA data. For present analyses, the outcome variable was min in vigorous physical activity, based on estimated intensity levels of 6 METs or higher. The rationale for limiting the outcome to vigorous intensity activities is the same as described above.

Test-retest reliability study. A separate study was conducted in Houston, TX to evaluate test-retest reliability of all surveys used in the study. Two surveys were completed by 105 parents of children aged 6 to 15 years $($ mean $=11.1, S D=$ 2.8). The sample was ethnically diverse with $60 \%$ non-white. Reliability was evaluated with oneway model intraclass correlations.

Data analysis. The first set of analyses was conducted with the 781 students with complete data for the survey. Parent-reported min of vigorous physical activity were log transformed to normalize the distribution. For each sex by grade grouping (i.e., grades 1-3, 4-6, 7-9, 10-12) bivariate correlations were computed between min of vigorous physical activity and all potential correlates. Significant correlates for each grade group were used in subsequent hierarchical linear regression models. Five blocks of variables were created, and they were entered into regressions in a standard order for each grade group. Demographic variables were entered first to adjust for non-modifiable correlates, so the models indicated whether other variables explained variance above that explained by demographics. Psychological and biological variables were entered second, because most intervention programs target changes in psychological mediators. Social variables were entered next, because a few intervention programs have targeted change in family and other social mediators. Environmental variables were entered last, because few studies have examined these potential mediators. The partial $r$ was computed for each variable to estimate the percent of variance in physical activity accounted for by each variable, adjusting for all other variables.

The second set of analyses was conducted on the 200 students with CSA monitor data. Because of small numbers, only four sex and grade subgroups were formed: males in grades 1-6, males in grades 7-12, females in grades 1-6, and females in grades 7-12. Partial correlations were computed for each subgroup between 20 potential correlates and vigorous physical activity, adjusting for age. Spearman partial correlations were used because the CSA variable was not normally distributed. Multiple regression analyses were not conducted because few variables were significant in bivariate correlations.

\section{Results}

\section{Associations With Parent-Reported Vigorous Physical Activity}

Table 2 shows the bivariate correlations of reported vigorous physical activity and 21 potential correlates for each sex and grade group. Five variables were significant in five of eight subgroups: enjoyment of physical activity, perceived coordination, 
use of recreational time, family influences, and peer influences. The Spearman correlations for these variables ranged from .20 to .52 . The only variable with a clear sex-related difference was enjoyment of physical education, which was significant for three of four female subgroups but no male subgroups.

Tables 3 and 4 show the results of the multiple regression analyses for males and females, respectively. The number of variables that were significant in bivariate correlations and entered into the regressions varied from two to eight. All of the regressions were significant, and adjusted $\mathrm{R}^{2}$ ranged from .11 to .36 .

For boys in grades 1-3, dual parent status (inverse) and peer support were significantly associated with vigorous physical activity. For boys in grades 4-6, no variables were significant, but enjoyment of physical activity was marginally significant $(p<.06)$. For males in grades $7-9$, use of recreation time and peer support were significant. For males in grades 10-12, significant contributors to the model were age (inverse) and ethnicity (minorities were higher). Partial r's for significant variables ranged from .07 to .25 .

For girls in grades 1-3, enjoyment of physical education and peer support were significant. For girls in grades 4-6, enjoyment of physical education was the only significant variable. For females in grades 7-9, use of recreational time and peer support were significant. For females in grades 10-12, use of recreational time and family support were significant. Partial r's for significant variables ranged from .04 to .24 .

\section{Associations with Vigorous Physical Activity Based on Activity Monitoring}

Table 5 shows partial correlations (controlling for age) between the CSA vigorous physical activity variable and 20 potential correlates for four subgroups. There were significant correlations in all subgroups. In the younger male group BMI was inversely correlated, whereas enjoyment of physical activity and perceived coordination were positively correlated. For older males, perceived coordination, peer influences, and use of recreational time were significant positive correlates. Peer influences was the only correlate for younger females, and frequency of using parks was the only correlate for older females.

\section{Discussion}

A set of 21 demographic, psychological, biological, social, and physical environmental variables explained important proportions of variance in vigorous physical activity of children and adolescents. The amount of variance explained was much lower in the youngest age group. More significant correlates were identified for parent-reported than for objectively measured youth vigorous physical activity. The amount of variance explained in the present study ranged from $11 \%$ to $36 \%$. This is somewhat less variance explained than in a recent study of children in grades 4 through 12, in which the range in variance explained was $18 \%$ to $59 \%$ (14). The latter study may have accounted for more variance because data were collected from youth and parents by telephone interviews, which may produce higher quality data.

In the multiple regression analyses to explain parent-reported physical activity only two variables were significant for several subgroups. Peer support was 
Vigorous Physical Activity - 39

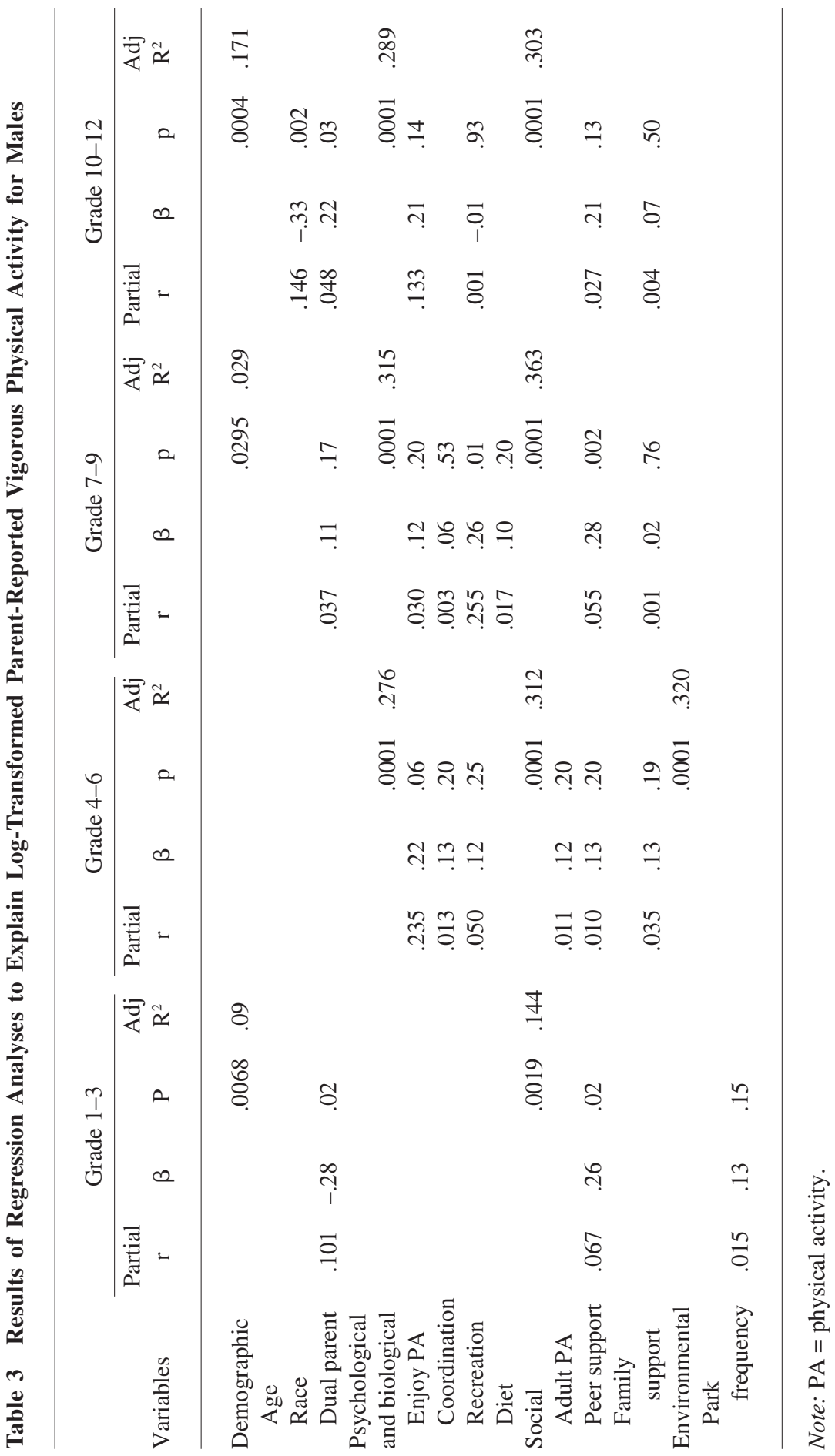


40 - Sallis et al.

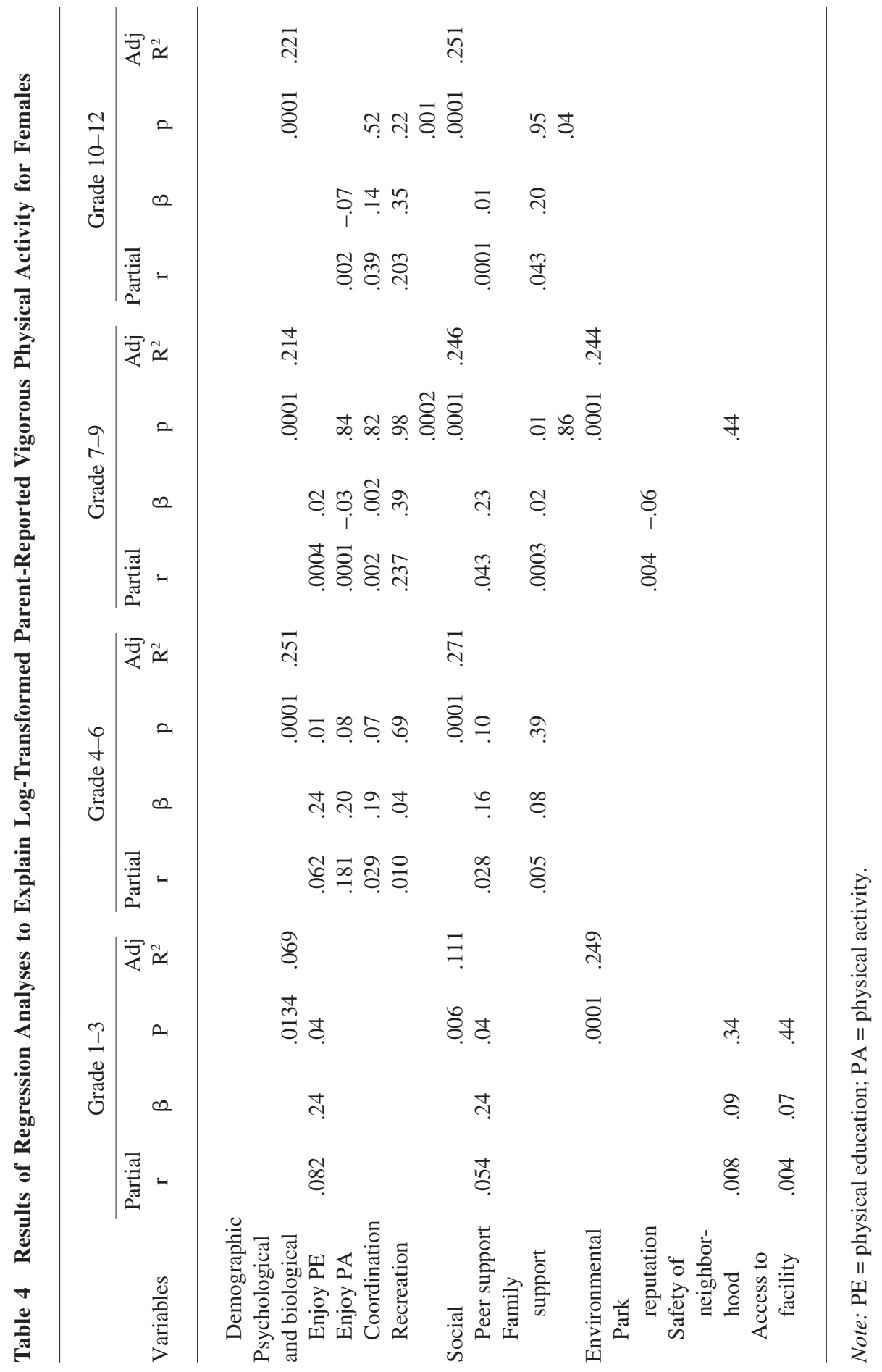


Table 5 Spearman Correlations of 20 Potential Determinants With Vigorous Physical Activity Assessed by the CSA Monitor, Partialling Out the Effects of Age

\begin{tabular}{lcccc}
\hline & $\begin{array}{c}\text { Younger } \\
\text { males } \\
n=34\end{array}$ & $\begin{array}{c}\text { Older } \\
\text { males } \\
n=52\end{array}$ & $\begin{array}{c}\text { Younger } \\
\text { females } \\
n=49\end{array}$ & $\begin{array}{c}\text { Older } \\
\text { females } \\
n=65\end{array}$ \\
Variables & & & & \\
\hline Race/ethnicity & -.17 & .16 & -.16 & .02 \\
Parent education & .07 & -.19 & -.09 & .13 \\
Dual parent status & -.09 & .01 & -.17 & .10 \\
No. children & -.06 & -.01 & -.01 & -.003 \\
BMI & $-.54^{* *}$ & .05 & -.21 & -.01 \\
School grades & .30 & -.04 & .18 & -.12 \\
Enjoyment of PE & .11 & -.16 & .07 & .17 \\
Enjoyment of PA & $.64 * * *$ & .23 & .17 & .11 \\
Coordination & $.40^{*}$ & $.37 *$ & .18 & .20 \\
Use of recreational time & .30 & $.36 *$ & .22 & .08 \\
Diet quality & -.05 & .09 & -.03 & -.16 \\
Family influences & .30 & .09 & .23 & .01 \\
Adult PA & .32 & .24 & .27 & -.11 \\
Peer influences & .01 & $.32^{*}$ & $.46 * *$ & .01 \\
Neighborhood characteristics & -.15 & -.03 & -.20 & .03 \\
Neighborhood safety & .16 & .09 & -.03 & -.12 \\
Access to facilities & .12 & .14 & .01 & .18 \\
Park Distance & -.05 & .06 & .28 & .09 \\
Park safety & .10 & -.17 & .17 & .10 \\
Park frequency & .05 & -.10 & -.04 & $.27 *$ \\
& & & & \\
\hline
\end{tabular}

Notes: Vigorous physical activity is minutes per day with intensity levels $\neq 6$ METs. $* p<.05, * * p<.01, * * * p<.001$

significant in two subgroups of females and two subgroups of males. Because this variable represented several types of peer influence, such as modeling and encouragement, it would be useful to determine which types of peer influence were most responsible for the association. It was interesting that peer support was significant in the youngest groups of girls and boys, because developmental theory predicts that family influences should decrease with age, while peer influences increase with age (2). Present results suggest that peer influences on physical activity are important even for young children.

Use of recreational time was significant in one subgroup of males and two subgroups of females. This result is consistent with a recent finding that use of after-school time for active versus sedentary pursuits was one of the most consistent correlates of physical activity across age and sex subgroups in a national sample of youth (14). Because most young people's discretionary time for recreation is immediately after school and on weekends, evidence is emerging that this time 
should become more of a focus for promoting physical activity. However, use of recreational time could be considered a partial proxy measure of physical activity, so the association may be overstated.

Enjoyment of physical education was a significant correlate for girls, but only up to grade 6 . Experiences in physical education classes may be particularly influential for younger girls. The activities, instructional methods, and organization of physical education merit more study so their effects on physical activity levels can be better understood. The related variable, enjoyment of physical activity, was significant in bivariate correlations but not in regression analyses. Potential multicollinearity between enjoyment of physical activity and physical education was determined not to be an important influence on results, due to correlations ranging from .22 to .48. Thus, present analyses suggest enjoyment of physical education is more important for girls than enjoyment of physical activity. This finding supports results of a previous study (14).

Although all the regression models explained $25 \%$ of the variance or more, except for the youngest age groups, in some models there were no significant individual variables. This pattern of results suggests that domains of variables, such as psychological or social, were important, but that no individual variables were sufficiently related to be significant on their own. Lower amounts of variance may have been explained for the youngest age groups because there was less variability in their activity levels, there was more error in the parent reports for this group, or the potential correlates were not as relevant.

The demographic domain was significant in three subgroups of males but explained modest amounts of variance. The psychological/biological and social domains explained substantial proportions of variance in almost all models. The environmental domain had a few significant associations in bivariate correlations, but this domain explained no variance in the regressions. Such a finding suggests that environmental variables work through other variables. For example, among boys in grades 4-6, use of recreation time could be related to the frequency they use a nearby park. Entering environmental variables last reduced the likelihood they would be significant.

Fewer significant correlations were observed with objectively measured vigorous physical activity, and results were less consistent than with parent-reported activity. However, perceived coordination, which was significant for most subgroups in parent-reported analyses were significant for younger and older males when examining objective physical activity. Peer influences, which were significant for all subgroups in parent-reported analyses, were significant for older males and younger females in analyses of the objective measure. Variance accounted for by significant variables ranged from .07 to .41 , indicating that variables such as enjoyment of physical activity and BMI (for younger males) had relatively strong associations. Present results are consistent with the study by Dishman et al. (4) that found higher correlations with self-reported than objectively measured physical activity in adults. Part of this pattern may be due to shared method variance in self-reported measures of physical activity and determinants. If objective measures are affected by activities that are not considered by participants when they complete self-reports of determinants, this could lower correlations. The monitor data could be adversely affected by lack of compliance in wearing the device and limitations of treadmill-based calibration equations. More studies of correlates using objective physical activity measures are needed, because the current results and 
the Dishman et al. (4) study indicate that most studies of physical activity correlates overestimate associations.

Limitations of this study included a low response rate, which could have reduced variance in some of the variables, affected the strength of associations, and reduced the generalizability of findings. Other limitations were the single geographic setting and use of unvalidated parent-report measures. The reliance on parent reports for child variables may be a substantial limitation, because parental reports of child activity levels have not been well supported in the literature (8) and may differ in accuracy depending on the age of the child. A preferable design for investigating developmental differences in correlates of youth physical activity would be to follow a large cohort of children, assessing a common core of potential correlates as the children age.

The present study had numerous strengths, the primary one being the collection of comparable data on children in grades 1 through 12 and their families. Previous studies reported many different variables and measures, which has hampered comparisons of findings across age groups. Because of the wide age range in the present study, it was necessary to use parent reports of potential determinants so the same variables could be examined across all ages. However, several variables were identified as significant in multiple age and sex subgroups. Comparisons of findings across reported and objectively measured physical activity have been rare, so the present study makes a substantial contribution to that literature. Another strength was the development of new measures that allowed more detailed examinations of social and environmental correlates of youth physical activity. Psychometric properties of survey variables, as indicated by test-retest and internal consistency reliabilities, were strong.

As in most studies, correlates of youth physical activity were identified in all domains, including demographic, psychological, social, and environmental. This supports the application of broad ecological models of behavior to studies of the correlates of physical activity. Most significant variables were in the psychological and social domains. The two most strongly supported correlates were peer support and use of recreational time.

\section{References}

1. Ainsworth, B.E., W.L. Haskell, A.S. Leon, D.R. Jacobs, Jr., H.J. Montoye, J.F. Sallis, and R.S. Paffenbarger, Jr. Compendium of physical activities: Classification of energy costs of human physical activities. Med. Sci. Sports Exerc. 25:71-80, 1993.

2. Buhrmester, D, and W. Furman. The development of companionship and intimacy. Child Develop. 58:1101-1113, 1987.

3. DeBourdeaudhuij, I. Behavioural factors associated with physical activity in young people. In: Young and Active? Young People and Health-Enhancing Physical Activity: Evidence and Implications, S. Biddle, J. Sallis, and N. Cavill (Eds.). London: Health Education Authority, 1998, pp. 98-118.

4. Dishman, R.K., C.R. Darracott, and L.T. Lambert. Failure to generalize determinants of self-reported physical activity to a motion sensor. Med. Sci. Sports Exerc. 24:904910, 1992.

5. Freedson, P.S., J. Sirard, E.P. Debold, S.G. Trost, M. Dowda, R.R. Pate, and J.F. Sallis. Calibration of a uniaxial accelerometer for estimating exercise intensity in children and youth. Manuscript submitted for publication. 
6. Melanson, E. L., Jr., and P. S. Freedson. Validity of the Computer Science and Applications, Inc. (CSA) activity monitor. Med. Sci. Sports Exerc. 27:934-940, 1995.

7. Pate, R.R., B.J. Long, and G. Heath. Descriptive epidemiology of physical activity in adolescents. Pediatr. Exerc. Sci. 6:434-447, 1994.

8. Sallis, J.F. Self-report measures of children's physical activity. J. School Health. 61:215219, 1991.

9. Sallis, J.F. Age-related decline in physical activity: A synthesis of human and animal studies. Med. Sci. Sport Exerc. 32:1598-1600, 2000.

10. Sallis, J.F., A. Bauman, and M. Pratt. Environmental and policy interventions to promote physical activity. Am. J. Prev. Med. 15:379-397, 1998.

11. Sallis, J.F., and M.F. Hovell. Determinants of exercise behavior. Exerc. Sports Sci. Rev. 18:307-330, 1990.

12. Sallis, J.F., M.F. Johnson, K.J. Calfas, S. Caparosa, and J. Nichols. Assessing perceived physical environment variables that may influence physical activity. Res. Quart. Sport. 68:345-351, 1997.

13. Sallis, J.F., J.J. Prochaska, and W.C. Taylor. A review of correlates of physical activity of children and adolescents. Med. Sci. Sports Exerc. 32:963-975, 2000.

14. Sallis, J.F., J.J. Prochaska, W.C. Taylor, J.O. Hill, and J.C. Geraci. Correlates of physical activity in a national sample of girls and boys in grades four through twelve. Health Psychol. 18:410-415, 1999.

15. Sirard, J.R., Melanson, E.L., Li, L., and Freedson, P.S. Field evaluation of the Computer Science and Applications, Inc. physical activity monitor. Med. Sci. Sports Exerc. 32:695-700, 2000

16. Taylor, W.C., T. Baranowski, and J.F. Sallis. Family determinants of childhood physical activity: A social-cognitive model. In: Advances in Exercise Adherence, R.K. Dishman (Ed.). Champaign, IL: Human Kinetics, 1994, pp. 319-342.

17. Taylor, W.C., and J.F. Sallis. Determinants of physical activity in children. In: World Review of Food and Nutrition (Vol.82). Nutrition and Fitness: Metabolic and Behavioral Aspects in Health and Disease, A.P. Simopolous and K.N. Pavlou (Eds.). Basel, Switzerland: Karger, 1997, pp. 159-167.

18. U.S. Department of Health and Human Services. Physical Activity and Health: A Report of the Surgeon General. Atlanta, GA: U.S. Department of Health and Human Services, Centers for Disease Control and Prevention, 1996.

19. Wold, B, and L. Hendry. Social and environmental factors associated with physical activity in young people. In: Young and Active? Young People and Health-Enhancing Physical Activity: Evidence and Implications, S. Biddle, J. Sallis, and N. Cavill, (Eds.). London: Health Education Authority, 1998, pp. 119-132.

\section{Acknowledgments}

The authors express warm appreciation to Diane Hermann of Cincinnatus, Inc. for her assistance in organizing and managing this project. This work was partially supported by a grant from the Cowles Media Foundation (Minneapolis, MN). 